\title{
JOVENS RURAIS DA ZONA DA MATA MINEIRA E PROJETOS DE VIDA PROFISSIONAL ${ }^{1}$
}

\section{RURAL YOUTH OF ZONE OF MATA MINEIRA AND PROFESSIONAL LIFE PROJECTS}

\author{
Solange Batista de Souza \\ Universidade Federal de Viçosa - Viçosa - MG - Brasil \\ Sheila Maria Doula \\ Universidade Federal de Viçosa - Viçosa - MG - Brasil \\ Pollyanna Maria Carmo \\ Universidade Federal de Viçosa - Viçosa - MG - Brasil
}

\begin{abstract}
Resumo: O artigo apresenta resultados da pesquisa "Possibilidades e condições de reprodução social no campo: estudo sobre a juventude rural da Zona da Mata Mineira". O trabalho teve como objetivo analisar a elaboração dos projetos de vida de jovens trabalhadores rurais e suas avaliações sobre as possibilidades regionais de concretizar os projetos. A metodologia usada foi a aplicação de questionário a 98 jovens de ambos os sexos, abordando as perspectivas sobre trabalho e futuro profissional. $\mathrm{O}$ artigo analisa a oferta de possibilidades regionais para o processo de formação e capacitação profissional principalmente para os jovens que demonstram interesse em permanecer no campo.
\end{abstract}

Palavras-chave: Jovens rurais. Trabalho. Zona da Mata Mineira. Políticas Públicas.

Abstract: This paper presents the results of the research named "Possibilidades e condições de reprodução social no campo: estudo sobre a juventude rural da Zona da Mata Mineira" (Possibilities and condition of social reproduction in the countryside: a study about rural youth in the region of Zona da Mata, Minas Gerais). The work had as objective analyzing the construction of young rural workers' projects of life and their review on the regional possibilities of making the projects come true. The survey consisted on the application of 98 questionnaires among male and female youngsters addressing issues on work and professional future. The paper studies de supply of regional possibilities to the process of professional formation and capacitation mainly to the youngsters that show interest in remaining in the countryside.

Keywords: Rural youth. Work. Zone of Mata Mineira. Public Policy.

\section{INTRODUÇÃO}

As transformações de ordem socioeconômica e tecnológica que estão ocorrendo nas últimas décadas têm provocado uma série de mudanças culturais que afetam as representações e os comportamentos do conjunto da sociedade, como por exemplo, os novos padrões de produção e consumo e a inserção de novas tecnologias, não sendo diferente com os habitantes do meio rural. A necessidade de compreender como essas transformações influenciam o trabalho, as relações sociais e os projetos de vida dos moradores do campo tem se configurado como um desafio contemporâneo para a formulação de políticas públicas de desenvolvimento local e regional, tornando-se, ao mesmo tempo, alvo

\footnotetext{
${ }^{1}$ Pesquisa financiada pela Fundação de Amparo à Pesquisa de Minas Gerais - FAPEMIG.
} 
de várias pesquisas acadêmicas nos últimos anos (PEREIRA, 2004; REIS, 2004; LOURENZANI, 2006).

Compreende-se que a definição do significado do conceito desenvolvimento esteja relacionada aos valores historicamente construídos em cada sociedade, ainda que permaneça em sua essência a conquista de padrões de vida mais elevados acessíveis à maioria da população (VIEIRA E SANTOS, 2012). Dessa forma, a elaboração de propostas e serviços para o meio rural se configura de forma decisiva para a melhoria de vida da população, resultando em um ambiente propício para o desenvolvimento.

Nesse aspecto, a juventude rural, entendida por Castro (2005) como agente de transformações, é um dos segmentos sociais que tem merecido atenção destacada dos pesquisadores, pois, por meio dele, é possível compreender não apenas como o mundo rural contemporâneo se caracteriza e é percebido pelos sujeitos que ali residem, mas também sugerir possibilidades e novas estratégias que visem à diminuição dos problemas vivenciados pelos jovens em sua inserção laboral, quer ela se dê no contexto rural, quer no contexto urbano.

No final do século $X X$, mais precisamente em sua última década, as pesquisas acadêmicas sobre juventude foram intensificadas no Brasil, e se concentraram, em maior número, na investigação sobre as condições de vida dos jovens moradores em áreas metropolitanas ou nas periferias urbanas. Cabe destacar aqui o levantamento do tipo "estado da arte" realizado por Sposito (2009) e também a análise histórica sobre o tema da juventude elaborada por Abramo (1997). Segundo as autoras, nesse período prevaleceram temas como pobreza, violência e exclusão social, demonstrando-se a urgência de conhecimento e também de formulação de políticas públicas capazes de enfrentar o "problema" juvenil. Essa prevalência fez com que Sposito (2009, p.24), alertasse que o foco nos estudos sobre a juventude urbana poderia "induzir a generalizações apressadas sobre a juventude brasileira, se não forem levadas em conta as condições de vida das pequenas e médias cidades e das zonas rurais".

Assim, na primeira década do século XXI, as pesquisas sobre jovens rurais se intensificaram - como demonstrou o levantamento bibliográfico e temático elaborado por Weisheimer (2005) -, seja para revisitar temas clássicos como o da migração juvenil para as cidades, por exemplo, seja na proposição de perspectivas inovadoras, que chamavam a atenção para a configuração da juventude rural como um novo ator social e político da sociedade brasileira (CASTRO, 2009).

No entanto, mesmo após ter ocorrido um aumento significativo de pesquisas sobre os novos significados atribuídos à ruralidade contemporânea e aos diferentes atores sociais que habitam o espaço rural, a necessidade de investigações sobre os jovens permanece, pois eles formam um segmento fundamental para as possibilidades de reprodução social no campo e para as estratégias de desenvolvimento rural.

Brumer (2007) argumenta que a migração dos jovens rurais insatisfeitos, principalmente com as condições de trabalho e com a falta de perspectivas no âmbito local, é uma temática recorrente na literatura, mas que ainda não se encontra resolvida. Assim, após alguns anos de formulação e implantação de políticas públicas voltadas à educação e ao trabalho da juventude rural, cabe questionar sobre o que mudou nos anseios dos jovens para o futuro e nos seus projetos de migrar ou de permanecer no meio rural. 
É nessa perspectiva que o presente artigo se vincula, ao analisar resultados da pesquisa "Possibilidades e condições de reprodução social no campo: estudo sobre a juventude rural da Zona da Mata Mineira", iniciada em 2013 e concluída em 2014. A pesquisa visou compreender a elaboração dos projetos de vida de jovens rurais da Zona da Mata Mineira e suas avaliações sobre as possibilidades de concretização desses projetos. Uma das metodologias utilizadas foi a aplicação de questionário com 98 jovens, de ambos os sexos, maiores de 18 anos e que se autodeclararam como trabalhadores.

\section{PERSPECTIVAS DOS ESTUDOS SOBRE AS JUVENTUDES}

Entre os caminhos percorridos pelos jovens é fundamental destacar que os processos de inserção no mundo do trabalho, de acesso à educação, as relações de consumo, de sociabilidade, as relações familiares e as maneiras de conhecer e vivenciar essa fase da vida podem variar de acordo com as diferenças de classe social, gênero, aspectos regionais, indicando uma pluralidade de situações juvenis.

Pais (1993) e Pereira (2004) argumentam que a juventude não pode ser compreendida por meio de um viés homogêneo, sendo ela múltipla, pois apesar das peculiaridades existentes nessa etapa da vida e dos mesmos desafios que se colocam à maior parte dos jovens no mundo atual, a forma de interpretá-los e enfrentá-los se processa de formas diferentes, devido ao contexto cultural, social e econômico nos quais os jovens estão inseridos.

Os estudos de Pais (2003) apontam para o fato de que não há somente uma juventude, portanto, é prudente que ela seja estudada a partir de sua historicidade e de suas formas próprias de estar no mundo. Para o autor é recomendável que:

os jovens sejam estudados a partir de seus contextos vivenciais, quotidianos, porque é quotidianamente, isto é, no curso das suas interações, que os jovens constroem formas sociais de compreensão e entendimento que se articulam com formas específicas de consciência, de pensamento, de percepção e ação (PAIS, 1993, p.56).

Ao concordar com Pais (1993) e explorar especificamente a definição de juventude rural, Pereira (2004) julga ser importante ressaltar que:

não podemos chegar a conceituar a juventude rural de modo generalizante. Talvez uma forma de visualizarmos a possibilidade dos jovens compartilhando certas características, seja descrever diferentes juventudes inseridas na dinâmica do desenvolvimento local (socioeconômico), apontando para a trajetória histórica do lugar - sua propriedade familiar e sua comunidade - os ritos que marcam a entrada e saída da juventude (PEREIRA, 2004, p.28).

De acordo com Castro et al. (2009), as pesquisas sobre a juventude rural brasileira têm incorrido no vício de focalizar apenas os filhos de agricultores familiares, não considerando os filhos dos grandes proprietários, os jovens empresários do meio rural e também os jovens de grupos tradicionais, fazendo 
com que o mapeamento das diversas situações de viver a juventude no meio rural se torne empobrecido.

Weisheimer (2005, p.25) também considera que, se tomarmos apenas a esfera do trabalho como exemplo, há uma gama relativamente grande de classificações de jovens trabalhadores que ainda não se encontra devidamente analisada, mostrando a necessidade de se falar em juventudes rurais, dado o espectro de variações de condições dentro desse universo social. O autor aponta as seguintes configurações e termos referidos à juventude rural: jovens agricultores, Jovens do campo, jovens do interior, jovens do sertão, jovens empreendedores rurais, jovens empresários rurais, jovens filhos de agricultores, jovens rurais ribeirinhos, jovens sem-terra, juventude em assentamento rural e juventude escolar rural. Essa configuração multifacetada mostra, por um lado, a dificuldade para as políticas públicas em abarcarem a totalidade de situações empíricas nas quais os jovens rurais se movem; mas mostra também, a grande quantidade de autodefinições que os jovens rurais utilizam para se referir a suas identidades laborais.

De acordo com Castro (2009), nos cenários rurais contemporâneos, os jovens vêm se firmando como atores sociais ativos na reconfiguração social, econômica e cultural que se processa, operando uma releitura de valores rurais e urbanos devido ao trânsito mais contínuo que realizam entre o campo e a cidade; essas leituras possibilitam a construção de novas sociabilidades, identidades e projetos de vida que, por sua vez, criam demandas contínuas nas esferas da representação política, da educação, do lazer e do trabalho.

Essas demandas podem operar como condições prévias para a permanência dos jovens no campo. Abramo (2005), Branco (2005) e Castro (2005) confirmam as dificuldades enfrentadas pelos jovens rurais no que tange ao acesso à escola e ao trabalho, e Carneiro (1998) aponta como fator principal responsável pelo êxodo rural juvenil certo "fascínio" e atração pelo estilo de vida urbano.

A partir dessas interpretações, este artigo parte do pressuposto que discutir a relação estabelecida entre juventude e o meio rural é mais do que pensar apenas a localização geográfica; envolve pensar historicamente as formas simbólicas de hierarquia construídas entre a cidade e o campo, que contribuíram para a formação de um projeto de vida carregado de valores positivos e negativos envolvendo esses espaços e seus estilos de vida.

A visão ainda presente na sociedade brasileira do espaço rural como um lugar atrasado influencia a construção do imaginário do sujeito inserido neste contexto, principalmente o jovem, que passa a visualizar na cidade a única possibilidade de melhores condições de reprodução social. Entretanto, como verse-á adiante, os jovens têm encontrado motivações subjetivas para permanecer no meio rural, restando-nos questionar, em contrapartida, quais condições objetivas eles demandam para que a permanência se realize com garantias de seus direitos sociais.

\section{JUVENTUDE RURAL E O MUNDO DO TRABALHO}

Discutir a relação entre juventude rural e trabalho requer mais do que analisar a escolha profissional e a obtenção de um emprego. Os jovens rurais, na 
maioria dos casos, além de começarem a contribuir com o trabalho da família desde cedo, também convivem com as dificuldades de acesso ao estudo.

Para Mello et al. (2003), se até o final da década de 1970 a profissão de agricultor era representada como uma obrigação moral de dar continuidade à tradição da família, e o conhecimento que o jovem adquiria no aprendizado com os mais velhos era tido como suficiente para gerir o estabelecimento agrícola, atualmente a agricultura é uma atividade que se transforma mais rapidamente, não só pelas novidades tecnológicas, mas também pela novas tendências alimentares dos consumidores e pelas exigências quanto à sustentabilidade ambiental, o que exige dos agricultores um nível educacional mais elevado e uma formação profissional contínua e atualizada.

Estudo e trabalho são as esferas da vida social juvenil que, segundo algumas pesquisas recentes (CASTRO, 2005; CARNEIRO, 2005; PAULO, 2011) permanecem como motivos explicativos para a migração dos jovens rurais. $O$ estudo tem assumido junto a esses jovens uma dimensão positiva que estava ausente das gerações passadas, e, como verificou Carneiro (2005), "a associação entre estudo e emprego é também generalizada, sendo o estudo encarado como a condição para, no falar de um jovem, 'ser alguém na vida' (CARNEIRO, 2005, p.249).

Em pesquisas qualitativas realizadas no nordeste brasileiro, Paulo (2011) argumenta que os jovens rurais atribuem à educação a possibilidade de melhor remuneração e de melhores condições de trabalho, uma vez que a atividade no meio rural não lhes oferece estabilidade financeira, tampouco a garantia de direitos trabalhistas.

Concordando com essa perspectiva, Castro (2005) ressalta que hoje a juventude rural se encontra diante da incerteza entre "sair e ficar" no campo não apenas devido aos limites e insuficiência da terra e à baixa renda familiar, mas também pela ausência de uma educação de qualidade.

Abramovay e Camarano (1998), focalizando a migração juvenil pelo prisma dos seus impactos na continuidade da vida social no campo, destacam que a migração para as cidades, sobretudo de jovens que partem em busca de melhores condições de trabalho e educação, tem contribuído para o enfraquecimento das famílias e comunidades rurais brasileiras. Os autores argumentam ainda, com base em estudos demográficos dos últimos 40 anos, que houve um processo de esvaziamento das populações rurais, e que a migração juvenil, principalmente feminina, provocou o envelhecimento e a masculinização do meio rural brasileiro.

Já pelo prisma dos próprios jovens, o deslocamento para as áreas urbanas é entendido como uma tentativa de conquistar um emprego formal, com carteira assinada, direitos trabalhistas, remuneração fixa, desenvolvimento pessoal e formas de assistência que resultem em melhor qualidade de vida, o que só reflete o "abandono a que foi submetido o mundo rural ao longo da história por parte dos governantes" (REIS, 2004, p.25).

Em meio ao debate sobre os motivos que levam os jovens a sair ou a permanecer no campo, Carneiro (2007) e Schneider (2007) defendem a tese de que a pluriatividade pode melhorar as condições de trabalho por meio da combinação de atividades agrícolas e não agrícolas desenvolvidas pela família dentro da propriedade rural. Carneiro (2007) enfatiza que as modificações no cenário rural, retirando dele a significação de um espaço exclusivamente agrícola, 
estão permitindo a incorporação de novas relações e práticas trabalhistas, como a remuneração mensal, férias, finais de semana remunerados e carteira assinada, que estão afetando os projetos dos jovens em relação ao futuro profissional, ao consumo e à cidadania. Para a autora, como o espaço rural está se tornando "cada vez mais heterogêneo, diversificado e não exclusivamente agrícola" (CARNEIRO, 1998, p.97), outras formas de obtenção de renda surgem no cenário de possibilidades, em particular para o segmento juvenil.

Schneider (2007) também defende que as novas atividades desenvolvidas no campo podem ser compreendidas como forma de valorização e preservação do modo de vida rural, e como fator fundamental do desenvolvimento local. Segundo o autor,

para avançar no estudo da pluriatividade propõe-se, enfim, situála no debate mais geral sobre o desenvolvimento rural. Para além de ser uma estratégia familiar e individual de reprodução social, a pluriatividade poderá contribuir de forma decisiva para ajudar a solucionar dificuldades e restrições que afetam as populações rurais, tais como a geração de emprego, o acesso à renda e sua estabilização, a oferta de oportunidades para jovens, entre outros (SCHNEIDER, 2007, p.7).

Também chamando a atenção para a responsabilidade das políticas de desenvolvimento rural, em relação aos projetos de futuro dos jovens, Carneiro (2007) alerta que a juventude rural não deve ser considerada como um coletivo homogêneo, pois regionalmente há várias formas de participação e inserção que podem potencializar ou restringir as aspirações juvenis. Assim, tão importante como compreender os projetos de vida desses jovens, é fundamental, também, investigar o campo (local e regional) de possibilidades disponíveis para a sua concretização.

\section{METODOLOGIA}

O presente trabalho analisa resultados obtidos na pesquisa intitulada "Possibilidades e condições de reprodução social no campo: estudo sobre a juventude rural da Zona da Mata Mineira". A pesquisa, de natureza quantitativa e exploratória, foi realizada na Universidade Federal de Viçosa, no campus-sede localizado no Município de Viçosa-MG. Os jovens pesquisados são participantes da $\vee$ Semana da Juventude Rural, evento promovido pela Empresa de Assistência Técnica e Extensão Rural de Minas Gerais - EMATER-MG, em parceria com o Projeto Transformar, do governo federal, e a Universidade Federal de Viçosa UFV.

A técnica utilizada para a coleta de dados foi a aplicação de questionário com questões fechadas e abertas para caracterizar como vivem os jovens em termos de escolaridade, trabalho e renda; nas questões abertas, buscou-se entender quais fatores são considerados limitantes ao desenvolvimento juvenil e quais são as perspectivas profissionais para o futuro. Foram aplicados questionários a 98 jovens rurais de ambos os sexos, com idade entre 18 e 29 anos, utilizando-se a técnica de autopreenchimento, que posteriormente foram sistematizados por meio do software Excel. A aplicação dos questionários ocorreu durante a $\mathrm{V}$ 
Semana da Juventude Rural, evento integrante da $89^{\circ}$ Semana do Fazendeiro, que teve como meta principal a capacitação de 250 jovens de diversas cidades da Zona da Mata Mineira, que participaram de cursos, palestras e oficinas voltadas para 0 desenvolvimento rural.

A Semana do Fazendeiro é uma iniciativa da UFV, em parceria com a EMATER, e sua primeira edição ocorreu em 1929. São oferecidas durante o evento diversas atividades culturais, como exposição fotográfica, dança, cinema, circuito de museus, oficinas, espetáculos musicais e teatro. Cerca de 150 expositores de máquinas agrícolas, veículos, artesanatos, plantas ornamentais e frutíferas, insumos agrícolas e outros produtos estão presentes todos os anos. Outras atividades relevantes do evento são os cursos oferecidos, como o "Troca de Saberes" e "Mulher Rural". O evento é sediado no campus da UFV, em ViçosaMG, cidade conhecida por ser um polo educacional da Zona da Mata Mineira.

A Zona da Mata localiza-se no sudeste do Estado de Minas Gerais, confrontando-se com os estados do Espírito Santo e Rio de Janeiro, e é composta por oito microrregiões e 143 municípios. A história econômica regional foi marcada pelo ciclo do café, mas a erradicação das lavouras com a crise cafeeira nos anos 1930 provocou uma reestruturação produtiva, quando alguns de seus principais municípios seguiram a via da industrialização. Esses municípios atualmente se constituem como polos microrregionais.

A região é favorecida por sua posição geográfica, que permite fácil comunicação com as principais capitais da Região Sudeste - Belo Horizonte, Rio de Janeiro e São Paulo -, tornando mais acessível o transporte da produção. A Zona da Mata conta com atividades agropecuárias e comerciais diversificadas; apresenta crescimento expressivo no setor de serviços e, mais recentemente, está criando programas para o turismo ecológico, com a presença de Unidades de Conservação, como por exemplo, o Parque Estadual da Serra do Brigadeiro e o Parque Estadual do Ibitipoca.

A população da pesquisa foi composta por 98 jovens, com idade média de 21 anos, sendo 14 participantes do sexo feminino e 84 do sexo masculino, moradores de 46 municípios da Zona da Mata (Figura 1). 
Figura 1. Mapa com localização da Zona da Mata Mineira e dos municípios de origem dos jovens participantes da pesquisa

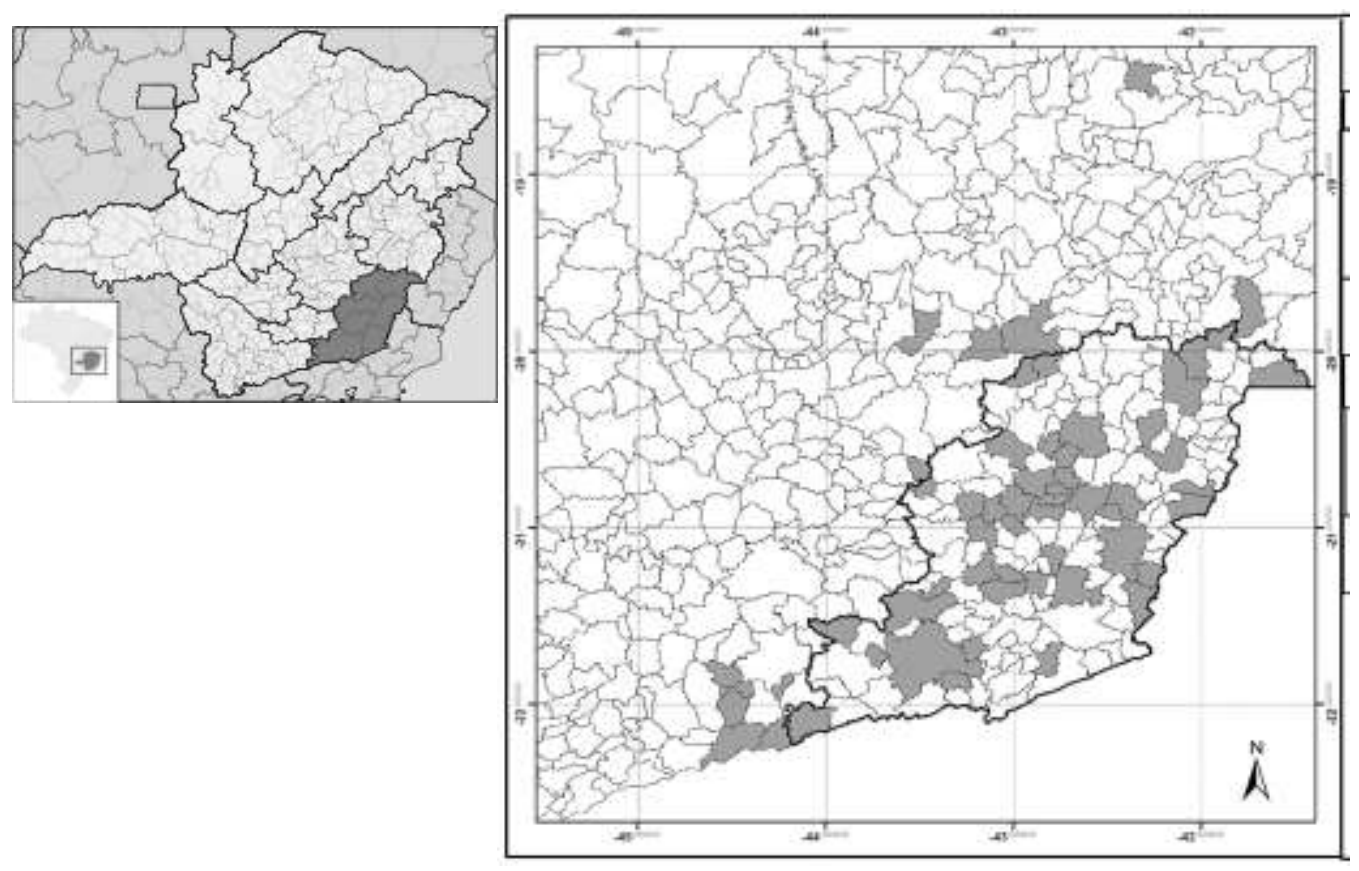

Fonte: Elaboração: Inácio Andrade Silva, 2014.

\section{RESULTADOS E DISCUSSÕES}

A primeira característica verificada em relação ao conjunto de jovens participantes da pesquisa refere-se ao local de moradia, com $84 \%$ residentes em áreas rurais e os demais em áreas urbanas de pequenas cidades do interior.

No conjunto pesquisado, $91 \%$ se autodeclararam trabalhadores, embora alguns jovens não tenham reconhecido atividades domésticas ou sazonais como trabalho. Destaca-se, ainda, que 84\% dos jovens trabalham sem carteira assinada, particularmente os que declararam realizar tarefas domésticas, atividades na agricultura e na pecuária ou trabalhos sazonais. Esse dado confirma outras pesquisas realizadas no Brasil e se constitui, ao mesmo tempo, em uma característica da pequena produção rural familiar e em fonte de exclusão social na visão dos jovens que trabalham no setor.

A propriedade da família foi citada como o lócus central de trabalho. Como os entrevistados puderam optar por mais de uma atividade, o trabalho na agricultura, na pecuária, as tarefas domésticas e o trabalho sazonal realizados na própria propriedade foram apontados por 82 jovens. Realizar essas mesmas atividades também em outras propriedades, foi opção de 12 jovens. Aqueles que trabalham fora das propriedades rurais e em atividades não agrícolas somaram 20 jovens. Neste último caso, os setores citados são o comércio (como açougue e mercearia), a indústria (de doces e de laticínios, típicos da região), e de serviços (serviços administrativos e no setor de turismo rural). Entre esses também foram verificados casos de ausência da carteira de trabalho. 
Em relação aos estudos, 56\% dos jovens afirmaram não estar estudando. O gráfico a seguir apresenta a situação de estudo e trabalho por gênero. Nas porcentagens relativas à opção "não estuda", deve-se considerar que as questões se referiam às modalidades de ensino formal, mas que os jovens estavam, no momento da aplicação dos questionários, realizando cursos de capacitação/atualização. Em segundo lugar, verifica-se que a opção "não trabalha" foi escolhida por jovens que realizam tarefas domésticas ("serviços de casa"), trabalho sazonal ou eventual (nas propriedades familiares ou em outras propriedades) (Figura 2).

Figura 2. Situação de trabalho e estudo dos jovens: A) Cruzamento entre gênero e situação de trabalho; B) Situação de trabalho das moças; C) Situação de trabalho dos rapazes. Resultado oriundo da amostragem de 14 moças e 84 rapazes

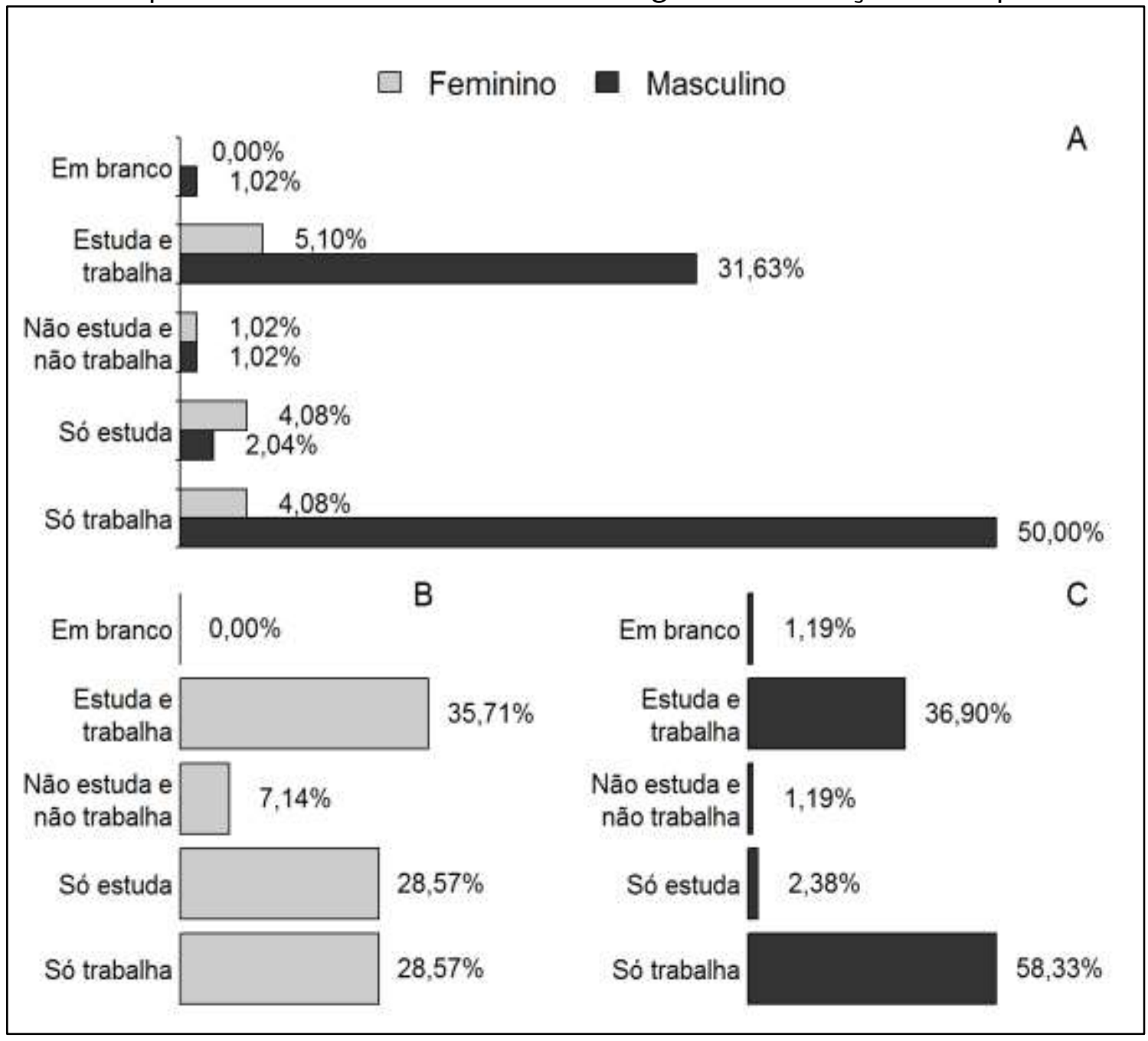

Fonte: Dados da pesquisa.

Os números apontam que, independentemente da idade, os estudos estão mais presentes na vida das jovens, confirmando uma tendência mais geral que mostra que as mulheres possuem mais oportunidades de continuidade dos estudos em função de não herdarem a propriedade rural e por serem excluídas dos processos produtivos nas propriedades familiares rurais (FERRARI et. al, 2004). 
Comparando-se os projetos de vida entre os gêneros, no entanto, a pesquisa não constatou maior tendência de migração entre as jovens. Assim, não se pode demonstrar para essa região uma tendência de masculinização.

Quando questionados sobre a profissão que gostariam de exercer no futuro, foram citadas várias áreas de atuação. As jovens optaram por carreiras nas áreas de Psicologia, Arquitetura, Pedagogia, Artes, Secretariado e Engenharia Ambiental, com forte tendência de exercê-las nas regiões onde residem atualmente.

Já as profissões citadas nos projetos de vida dos jovens indicam uma composição que incide prioritariamente para a área agrária. Foram escolhidas tanto as profissões que denotam a exigência de formação em curso superior, como "médico veterinário" e "engenheiro agrônomo", como também aquelas que dão continuidade às atividades que eles já estão exercendo, como "continuar agricultor", "ser um bom produtor rural", "pecuarista de leite", dentre outras (Figura 3).

Figura 3. Projetos profissionais dos 98 jovens entrevistados

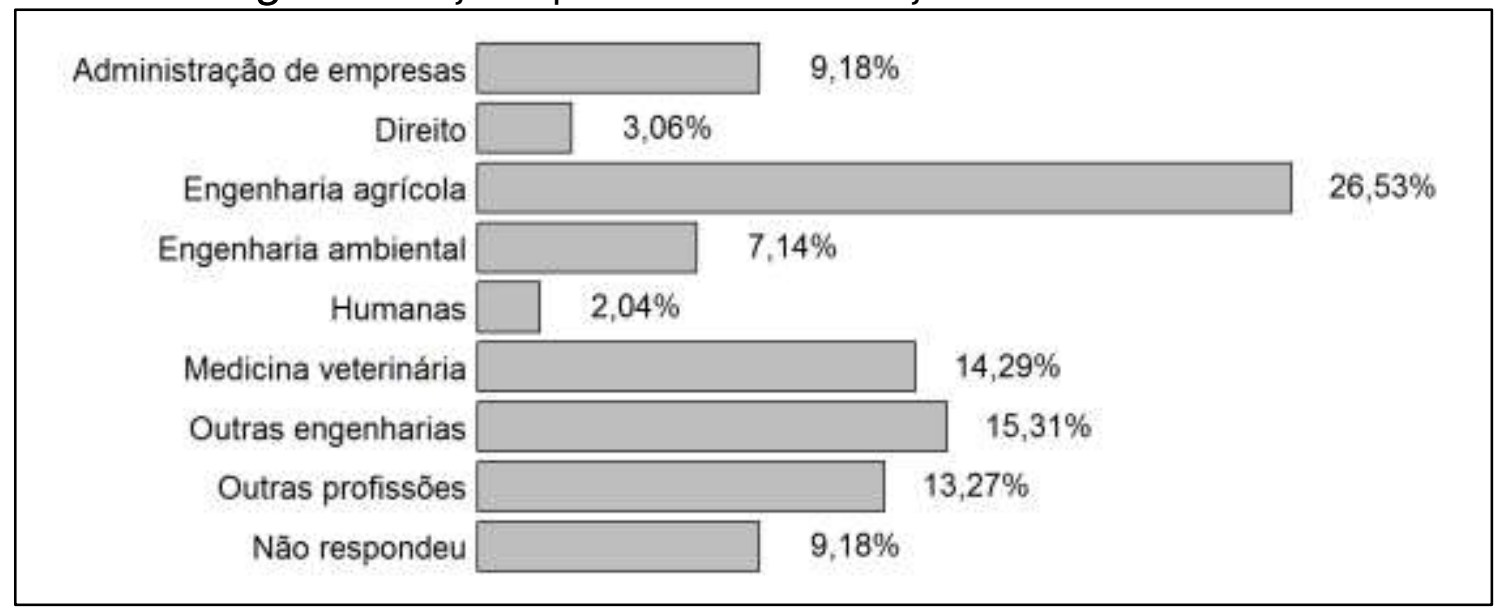

Fonte: Dados da pesquisa.

Nota-se que, se considerarmos Engenharia Agrícola, Engenharia Ambiental e Medicina Veterinária como cursos superiores que em muitas universidades estão situadas nas Ciências Agrárias, a porcentagem de jovens que planejam exercer profissões relacionadas ao meio rural chega à metade dos participantes da pesquisa. Porém, vale destacar que a escolha de atividades não agrárias não significa abandonar a vida no campo.

Para aqueles que optaram por desenvolver atividades agropecuárias, os projetos são de continuidade nas propriedades familiares, mas incorporando conhecimentos técnicos e inovações tecnológicas que pretendem adquirir em cursos superiores ou de capacitação e atualização. Nesse sentido, os dados coletados na pesquisa corroboram o argumento de Carneiro (2007), que ressalta que, para que os jovens permaneçam no campo, faz-se necessário pensar em alternativas não agrícolas, ou, "ao menos em um modo de fazer agricultura diferente de seus pais" (CARNEIRO, 2007, p.61).

Os dados apontam que, além do setor agropecuário, outros interesses demonstrados pelos jovens recaem sobre a área chamada por eles de "meio ambiente" ou "alguma coisa ligada à natureza", havendo menção clara à 
demanda por um curso superior. É importante destacar que os serviços ligados à proteção ambiental fazem parte da multifuncionalidade atribuída ao espaço rural, e que a região da Zona da Mata possui Unidades de Conservação federais, estaduais e municipais que, em tese, criam um campo de possibilidades para a concretização desses projetos profissionais.

Das ocupações não-agrícolas, verificou-se, nos questionários, que a área das engenharias foi assinalada com maior grau de especificidade: mecânica, mecatrônica, da computação, química e civil. Os jovens que optaram por essas profissões são do sexo masculino, e dentre eles está a maior porcentagem de tendência à migração, inclusive internacional. Já na categoria "Outros", foram citadas as atividades de costureira, peão de rodeio, verdureiro e cozinheiro, não havendo menção sobre a necessidade ou existência de curso superior ou de capacitação para exercê-las. Destaca-se ainda que, nessa categoria, várias profissões estão ligadas ao mundo rural, como "técnico extensionista da EMATER" ou "analista e gestor da agricultura familiar", por exemplo.

Quando questionados sobre a existência de cursos de formação/capacitação para a profissão desejada em sua região, 62\% dos jovens afirmaram negativamente, $32 \%$ confirmaram a existência de cursos profissionalizantes onde moram e 6\% não responderam. Esses dados, no entanto, devem ser relativizados, pois algumas das atividades escolhidas para o futuro dos jovens podem ser entendidas por eles como essencialmente empíricas, como a de "agricultor", "verdureiro", "costureira" ou "peão de rodeio", daí não indicarem a existência ou o conhecimento sobre os cursos específicos. Além disso, houve a menção aos cursos à distância (EAD), o que leva os jovens a amenizarem as carências da oferta de ensino presencial nas localidades mais próximas ao local de residência.

Mesmo assim, as informações obtidas no presente estudo demonstram a defasagem em relação à oferta de capacitação do jovem rural, o que fragiliza a concretização de seus projetos profissionais. Vale destacar que, embora a Zona da Mata Mineira possua duas universidades federais, dentre as quais a UFV, que prioriza sua identidade institucional na área das Ciências Agrárias, ela foi citada apenas duas vezes pelos jovens, e que a Universidade Federal de Juiz de Fora UFJF não obteve nenhuma referência. Assim, apesar de estarem na UFV para participar dos cursos da Semana da Juventude Rural no momento em que a pesquisa foi realizada, os jovens não reconheceram a instituição como um horizonte provável para a sua formação profissional.

Em relação ao local em que pretendem exercer a profissão desejada, a grande maioria afirma que espera permanecer na região em que vive. Para aqueles que pretendem migrar, outras regiões do próprio Estado de Minas Gerais foram as mais citadas (Figura 4). Foi possível verificar também que, para aqueles que reconheceram a necessidade de sair para buscar formação profissional, o tempo de ausência é limitado, ou seja, há um prazo estipulado para retornarem ao local de origem. 
Figura 4. Resultados do local pretendido para exercício da futura profissão.

Pesquisa realizada com 98 jovens

\begin{tabular}{|c|c|c|}
\hline Em branco & $7,14 \%$ & \\
\hline Em outras reigões do estado & $11,22 \%$ & \\
\hline Em outro estado do pais & $5,10 \%$ & \\
\hline Em outro pais & $3,06 \%$ & \multirow[b]{2}{*}{$73,47 \%$} \\
\hline Na sua regiāo & & \\
\hline
\end{tabular}

Fonte: Dados da pesquisa.

Quando interrogados sobre onde pretendiam viver no futuro, 65 jovens responderam que pretendem continuar vivendo no campo, 19 participantes afirmaram que pretendem se mudar para a cidade, e 14 jovens não responderam a pergunta. A maior parte dos jovens pesquisados ressaltou que gosta de viver no campo, compreendendo o meio rural como um lugar "de onde se vê e se vive o mundo" (WANDERLEY, 2004, p.81).

Entre os jovens que responderam ter como projeto de vida a permanência no campo, destaca-se a motivação de ordem subjetiva dos aspectos positivos que mais valorizam na vida no campo, como tranquilidade, liberdade, contato com a natureza, o custo de vida mais baixo e qualidade de vida. De acordo com a fala dos jovens: "a tranquilidade possibilita muito o conforto, onde se tem mais liberdade com menos riscos e com mais qualidade de vida" (J.P.F;19 anos).

Já entre os que pretendem se mudar para a cidade, o principal motivo reside em obter emprego no qual a remuneração seja mais alta que a oferecida pelo meio rural, seguido de melhores condições para estudar e também para ter acesso a novas tecnologias. De acordo com um dos jovens, nas cidades "tem mais oportunidades, mais fácil para estudar, arrumar um emprego, e pelo fato de na cidade gerar muitas oportunidades para as pessoas" (A.S; 21 anos).

Nesse aspecto, a pesquisa confirma as análises de Wanderley (2007), quando a autora ressalta que ao mesmo tempo em que as cidades são compreendidas pelos jovens rurais de modo negativo devido a fatores como drogas e violência, "ela também é valorizada positivamente por constituir um centro de serviços e oferecer possibilidades de progresso e educação, como complemento necessário à vida no meio rural" (WANDERLEY, 2007, p.38).

É valido ressaltar que, para os jovens aqui pesquisados, voltar ou continuar a viver no campo pode não estar relacionado à falta de oportunidades no meio urbano, ou ao "medo de sobrar", como avaliou Stropasolas (2007), referindo-se à competitividade que as redefinições produtivas impostas pela globalização e pelas inovações tecnológicas impuseram ao mercado de trabalho urbano. A avaliação dos jovens da Zona da Mata recai, como mostrou a pesquisa, na preponderância de critérios ligados ao pertencimento coletivo e aos laços familiares como as principais influências na decisão de onde planejam estar no futuro. No entanto, como ressaltou Pochmann (2004), a crise do trabalho no Brasil vem sendo responsável pela distinção cada vez maior entre como os jovens gostariam de viver no futuro - as perspectivas, os ideais, os projetos de vida - e o que eles realmente conseguem alcançar - a forma com que acabam tendo que lidar com a realidade 
que lhes são impostas no dia a dia - não lhes deixando muita escolha sobre a profissão desejada.

\section{CONSIDERAÇÕES FINAIS}

Os dados que resultaram da pesquisa permitem apontar que, na avaliação que os jovens fazem sobre as possibilidades concretas que estão regionalmente disponíveis para o sucesso de seu futuro profissional, destaca-se a ausência de políticas públicas e de instituições que atendam às peculiaridades juvenis no meio rural. Embora uma grande parcela dos jovens afirme a intenção de morar no campo e trabalhar em atividades agrícolas, é importante destacar que os mesmos não identificam condições de acesso à formação e à capacitação profissional, a despeito de haver na região uma infraestrutura de ensino que negue essa percepção juvenil.

A pesquisa aponta, assim, para a necessidade de aprofundamento sobre as situações empíricas nas quais os jovens rurais estão imersos, e que nem mesmo as políticas públicas atuais de democratização de acesso ao ensino ou de interiorização do ensino superior estão contemplando. Aponta, ainda, para a formulação de algumas hipóteses que permitam interpretar porque certas políticas se revestem de invisibilidade na concepção dos jovens.

Como frisado no início deste artigo, a pesquisa se concentrou em jovens trabalhadores rurais, o que equivale a dizer que, independentemente do grau de escolaridade, os jovens já integram um universo laboral específico no qual a dispensa e o afastamento de um membro da família para estudar fora compromete a quantidade de trabalho a ser redistribuída ou a renda a ser auferida. Assim, há um custo social não previsto pelas políticas públicas de educação para o meio rural, que incide diretamente na qualidade de vida da família como um todo. Além disso, há que se destacar os custos, nesse caso, financeiros, para o deslocamento e a manutenção dos jovens rurais nas cidades no período da qualificação profissional, o que, em contextos de pobreza, sequer pode ser cogitado.

Um segundo aspecto diz respeito a como profissionalizar os jovens rurais e com qual perspectiva de futuro. Se é certo que a formação de nível superior, como os próprios jovens acreditam, pode ampliar as oportunidades de um futuro melhor, nada garante que o desejo de retornar ao local de origem para exercer a profissão seja acompanhado de políticas públicas locais para a absorção dessa mão de obra qualificada. Assim, o sonho da educação meramente com vistas à empregabilidade pode se ver frustrado, na medida em que os projetos de desenvolvimento rural não se comprometam com esse nível de inclusão laboral e social que os jovens esperam.

Finalmente, os dados da pesquisa permitiram constatar o peso conferido pelos jovens aos significados negativos que o afastamento da segurança da família e dos laços de pertencimento identitário podem assumir, mesmo que temporariamente, diante da possibilidade de maior escolarização e profissionalização. Assim, se o aumento da oferta de oportunidades de acesso ao ensino superior pode ser interpretado como inegável fator de inclusão social, para alguns segmentos juvenis ele implica também uma fase conflitante de exclusão, 
quando os jovens sentem a possibilidade da desvinculação de coisas e pessoas que lhes são caras.

Somados esses fatores, a pesquisa sugere que há um grau de desconfiança juvenil em relação ao futuro, não apenas porque o amanhã pode estar calcado em falsas promessas, mas também porque, para concretizá-lo, os jovens rurais tenham que passar por momentos difíceis de rupturas em relação a alguns valores morais e subjetivos, aos quais, ao menos por ora, eles pretendem dar continuidade.

\section{REFERÊNCIAS}

ABRAMO, H. W. Considerações sobre a tematização social da juventude no Brasil. Revista Brasileira de Educação. Maio/jun./jul./ago., n. 05, n. 06, 1997.

ABRAMO, H. W. \& BRANCO P. P. M. (org.) Retratos da juventude brasileira: análises de uma pesquisa nacional. São Paulo: Editora Fundação Perseu Abramo. 2005.

ABRAMOVAY, R. et. al. Juventude e agricultura familiar: desafio dos novos padrões sucessórios. Brasília: Edições UNESCO, 1998.

BRAVERMAN, H. Trabalho e capital monopolista. Rio de Janeiro: Editora LTC, 1987.

BRUMER, A. A problemática dos jovens na pós-modernidade. In: CARNEIRO, M.J.; CASTRO, E. G. (Org.). Juventude rural em perspectiva. Rio de Janeiro: Editora Mauad, 2007.

CAMARANO, A. A.; ABRAMOVAY, R. Éxodo rural, envelhecimento e masculinização no Brasil: panorama dos últimos cinquenta anos. Revista Brasileira de Estudos de População, v. 15, n. 2, p. 45-66, julho/dezembro, 1998.

CARNEIRO, M. J. Juventude rural: projetos e valores. In: ABRAMO, H.; BRANCO; P. P. M. (Org.). Retratos da juventude brasileira: Análise de uma pesquisa nacional. São Paulo: Editora Fundação Perseu Abramo, 2005.

O ideal rurbano: campo e cidade no imaginário de jovens rurais. In: TEIXEIRA DA SILVA, F. C., SANTOS, R., COSTA, L. F. C. (Org) Mundo rural e política. Ensaios interdisciplinares. Rio de Janeiro: 1998.

Juventude rural: projetos e valores. In: Abramo, H.W. ; Branco, P.P.M. (Orgs.). Retratos da Juventude Brasileira. São Paulo: Editora Fundação Perseu Abramo/Instituto Cidadania, p.243-262, 2005.

Juventude e novas mentalidades no cenário rural In: CARNEIRO, M.J.; CASTRO, E.G. de (Org.). Juventude rural em perspectiva. Rio de Janeiro: Editora Mauad, 2007. 
CASTRO, E. G. Entre ficar e sair: uma etnografia da construção social da categoria juventude rural. Tese de Doutorado. PPGAS- Museu Nacional, UFRJ, 2005.

CASTRO, E. G. \& MARTINS, M. Os jovens estão indo embora? Juventude rural e a construção do ator político. Rio de Janeiro: Editora EDUR, 2009.

CORREA, L. M. Entre apropriação e a recusa: os significados da experiência escolar para jovens de periferias urbanas. São Paulo: Editora da UNESP, 2011.

CORROCHANO, M. C. Jovens trabalhadores: expectativas de acesso ao ensino superior. Avaliação. v. 18, n. 1, Sorocaba, p. 23-44, 2013.

CUNHA, M. A. de A. Expectativas de jovens camponeses na universidade: os desafios de uma formação em nível superior. Inter-Ação, v. 36, n. 1, Goiânia, p. 263-283, jan./jun., 2011.

FERRARI, D. L. et al. Dilemas e estratégias dos jovens rurais: ficar ou partir? Estudos Sociedade e Agricultura, Rio de Janeiro, vol. 12, n. 2, p. 237-271, 2004.

GARCIA, D. M. F. Juventude em tempos de incertezas: enfrentando desafios na educação e no trabalho. São Paulo: Editora ANNABLUME, 2009.

LOURENZANI, W. L. Capacitação gerencial de agricultores familiares: uma proposta metodológica de extensão rural. In: Organizações Rurais e Agroindustriais/Revista de Administração da UFLA, vol. 8, n.3, Lavras, MG: set./dez., 2006.

MELLO. M., A., SILVESTRO1. M. L.ABRAMOVAY. R, DORIGON1, C. FERRARI1 D., L. TESTA1 , V. M. Educação formal e os desafios para a formação de uma nova Geração de agricultores. In: XLI CONGRESSO DA SOBER-Sociedade Brasileira de Economia e Sociologia Rural. Juiz de Fora, MG, 27 a 30 de julho de 2003.

PAIS, J. M. Culturas Juvenis. Lisboa: Imprensa Nacional - Casa da Moeda, 2003.

PAULO, M. A. L. Juventude Rural: suas construçôes identitárias. Recife: Editora Universitária da UFPE, 2011.

PEREIRA, J. L. G. Juventude Rural: para além das fronteiras entre campo e cidade. (Tese de doutorado em Sociedade e Agricultura). Seropédica: UFRRJ, 2004.

POCHMANN, M. Desafios do trabalho. Petrópolis, RJ: Editora Vozes, 2004.

REIS, E. S. Educação do Campo e Desenvolvimento Rural Sustentável: avaliação de uma prática educativa. Juazeiro, Bahia: Editora Franciscana, 2004.

SCHNEIDER, S. A pluriatividade no meio rural brasileiro: características e perspectivas para investigação. In: GRAMMONT, H. C.; MARTINEZ VALLE, L. 
(Org.). La pluriactividade en campo latino americano. México: Editora Flacso, p. 132-161, 2007.

SPOSITO, M. Estado da arte na pós-graduação brasileira: educação, ciências sociais e serviços sociais (1999-2006). Belo Horizonte: Editora Argvmentvm: 2009.

Transversalidades no estudo sobre jovens no Brasil: educação, ação coletiva e cultural. Revista Educação e Pesquisa, v. 36, n. especial, São Paulo: 2010.

STROPASOLAS, V. L. O mundo rural no Horizonte dos jovens. Florianópolis Editora da UFSC, 2006.

. Um marco reflexivo para a inserção social da juventude rural. In: CARNEIRO, M. J; CASTRO, E. G. (Org.). Juventude rural em perspectiva. Rio de Janeiro: Editora Mauad X, p. 279-296, 2007.

TARTUCE, G. Jovens na transição escola-trabalho: tensões e intenções. São Paulo: Editora ANNABLUME, 2010.

VIEIRA, E. T.; SANTOS, M. J. Desenvolvimento econômico regional - uma revisão histórica e teórica. Revista Brasileira de Gestão e Desenvolvimento Regional, v. 8, n. 2, p. 344-369, Taubaté, SP, Brasil, maio/ago., 2012.

WANDERLEY, M. N. B. Jovens rurais de pequenos municipios de Pernambuco: que sonhos para o futuro. In: CARNEIRO, M. J.; CASTRO, E. G. (Org.). Juventude Rural em perspectiva. Rio de Janeiro: Editora Mauad X, p. 21-33, 2007.

WEISHEIMER, N. Juventudes rurais: mapa de estudos recentes. Brasília: Ministério do Desenvolvimento Agrário, Estudos Nead, Vol. 7, 2005. 


\section{Sobre as autoras}

Solange Batista de Souza

Mestre em Extensão Rural (UFV). Professora do Instituto Federal de Goiás.

Rua João Henrique Duarte, 194, Apto 201, Itumbiara-GO

E-mail: solange.souza@ifg.edu.br

\section{Sheila Maria Doula}

Doutora em Antropologia Social (USP). Professora Associada IV do Programa de Pós-graduação em Extensão Rural da Universidade Federal de Viçosa-MG. Coordenadora do Observatório da Juventude Rural-UFV.

Rua Ervália, 89, Viçosa-MG

E-mail: sheila@ufv.br

\section{Pollyanna Maria Carmo}

Bacharel em Cooperativismo (UFV).

Rua Itapecerica, 2.590, Divinópolis-MG

E-mail: polly_carmo@hotmail.com 